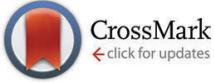

Cite this: New J. Chem., 2016, 40, 1213

Received (in Montpellier, France) 28th September 2015, Accepted 18th November 2015

DOI: 10.1039/c5nj02639c

www.rsc.org/njc

\section{The synthesis and characterization of tributyl phosphate grafted carbon nanotubes by the floating catalytic chemical vapor deposition method and their sorption behavior towards uranium}

\author{
Shruti Mishra, ${ }^{\text {ab }}$ Jaya Dwivedi, ${ }^{\text {b }}$ Amar Kumar $^{\mathrm{c}}$ and Nalini Sankararamakrishnan*a \\ Carbon nanotubes (CNTs) were synthesized by the floating catalytic chemical vapor deposition technique \\ using ferrocene in benzene as the hydrocarbon source. The functionalization of CNTs was carried out by \\ oxidation (CNT-OX) and grafting with a tributyl phosphate (TBP) ligand (CNT-TBP). Various spectroscopic \\ techniques including scanning electron microscopy (SEM), Fourier Transform Infra Red Spectroscopy \\ (FTIR), BET surface area and X-ray photoelectron spectroscopy (XPS) were used to characterize the \\ adsorbents. FTIR and XPS studies revealed the efficient grafting of the TBP ligand on the CNT surface. \\ The effect of the initial $\mathrm{pH}$ and the contact time for the maximum adsorption of $U(\mathrm{vl})$ with CNT-plain, \\ CNT-OX and CNT-TBP was studied. The spontaneity of the sorption was confirmed by thermodynamic \\ data. A pseudo second order model with a regression coefficient of $>0.978$ was obtained for CNT-TBP \\ and equilibrium was reached within $3 \mathrm{~h}$. The Langmuir maximum adsorption capacity of $\mathrm{U}(\mathrm{VI})$ at $\mathrm{pH} 5$ for \\ CNT, CNT-OX and CNT-TBP was found to be $66.6,100.0$ and $166.6 \mathrm{mg} \mathrm{g}^{-1}$ respectively. Using $0.1 \mathrm{M}$ \\ $\mathrm{HCL}$ as a desorbent, recyclability studies were carried out for three cycles. The probable mechanism of \\ adsorption between $\mathrm{U}(\mathrm{VI})$ and CNT-TBP could be understood through FTIR and XPS techniques.
}

\section{Introduction}

Advanced treatment methods are required for the management of radioactive waste produced by nuclear power plants. ${ }^{1,2}$ Uranium is one of the major waste materials in spent nuclear fuels or mine tailings, and it can cause significant contamination. ${ }^{3}$ An exposure level of $0.1 \mathrm{mg} \mathrm{kg}^{-1}$ of body weight of natural $\mathrm{U}$ could result in kidney damage. ${ }^{4}$ The World Health Organization's guideline value for uranium is set at $50 \mu \mathrm{g} \mathrm{L} \mathrm{L}^{-1.5}$ Several methods have been found to be useful for the removal of uranyl ions from process effluents and wastewater. For water treatment, compared to other techniques adsorption has been found to be a preferred technique owing to its flexibility, cost effectiveness, ease of operation and simple design. A weak affinity and low adsorption capacity are exhibited by natural adsorbents for $\mathrm{U}(\mathrm{vI})$ under ambient conditions. Therefore, there is a need for new, eco-friendly and economical adsorbents with high adsorption capacities and

\footnotetext{
${ }^{a}$ Centre for Environmental Science and Engineering, Indian Institute of Technology Kanpur, Kanpur, U.P. 208016, India.E-mail: nalini@iitk.ac.in; Tel: $+91-5122596360$

${ }^{b}$ Department of Chemistry, Banasthali Vidyapith, Rajasthan 304022, India

${ }^{c}$ Bhabha Atomic Research Centre, Trombay, Mumbai, India
}

stronger chemical interaction towards $\mathrm{U}(\mathrm{vI})$. Among the various adsorbents reported in the literature, sorption materials made of carbon offer a variety of advantages including high thermal and radiation resistance and improved chemical stability under acidic conditions compared to other inorganic sorbents and ion exchange resins. ${ }^{6}$ Various carbonaceous materials like activated carbon, ${ }^{7,8}$ activated carbon fibers, ${ }^{9}$ carbon nanotubes ${ }^{10,11}$ and mesoporous carbon ${ }^{12}$ have been reported for the removal of $\mathrm{U}(\mathrm{VI})$ ions from aqueous solution. Tributyl phosphate (TBP) is one of the widely used extractants for the removal of $\mathrm{U}(\mathrm{vI}) .{ }^{13}$ Thus, in this work three kinds of carbon nanotubes namely plain CNTs, oxidized CNTs and TBP grafted CNTs structurally characterized by various techniques will be prepared and evaluated for the removal and recovery of $\mathrm{U}(\mathrm{vI})$. Using spectroscopic tools the adsorption mechanism between $\mathrm{U}(\mathrm{vI})$ and CNT-TBP will also be discussed.

\section{Materials and methods}

All reagents and chemicals like nitric acid $\left(\mathrm{HNO}_{3}\right)$, sodium hydroxide $(\mathrm{NaOH})$, tributyl phosphate (TBP), uranyl(vi) nitrate $\left(\mathrm{UO}_{2}\left(\mathrm{NO}_{3}\right)_{2} \cdot 6 \mathrm{H}_{2} \mathrm{O}\right)$, solvents (ethanol, acetone) and other reagents 
used in this study are of analytical grade. Using Milli-Q purified water (resistivity $>18.2 \mathrm{M} \Omega \mathrm{cm}$ ) the reagents and standards were prepared.

\subsection{Preparation of carbon nanotubes}

Carbon nanotubes were prepared by the floating catalyst horizontal chemical vapour deposition technique using $2 \%$ ferrocene in benzene as the hydrocarbon source. ${ }^{14}$ The flow rate of the ferrocene/benzene solution and nitrogen gas was controlled using a peristaltic pump and a mass flow controller (Bronkhorst high-tech. Netherlands), respectively. The temperature of the electric furnace was gradually increased to $800{ }^{\circ} \mathrm{C}$ under a nitrogen atmosphere. The flow rates of the ferrocene/benzene

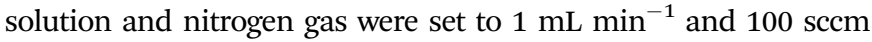
respectively and the ferrocene/benzene solution was pumped into the reactor for $30 \mathrm{~min}$ at an $800{ }^{\circ} \mathrm{C}$ reactor temperature. The reactor was gradually cooled to room temperature. The deposited CNTs were removed and used for further experiments.

\subsection{Preparation of CNT-OX}

Around $1 \mathrm{~g}$ of plain CNTs was heated with $10 \mathrm{ml}$ of nitric acid at $80{ }^{\circ} \mathrm{C}$ until the acid evaporated completely. Then, a thorough washing with distilled water was carried out until the $\mathrm{pH}$ of the filtrate became neutral. Finally, the obtained product was dried in an oven at $70{ }^{\circ} \mathrm{C}$ overnight and used for further experiments.

\subsection{Preparation of CNT-TBP}

One gram of CNT-OX was treated with $20 \mathrm{~mL}$ of tributyl phosphate and the solution was sonicated for $24 \mathrm{~h}$. Then, the obtained mixture was washed using distilled water and dried at $70{ }^{\circ} \mathrm{C}$ overnight and used for further experiments.

The preparation of CNT-OX and CNT-TBP is shown in Scheme 1.

\subsection{Batch studies}

Using batch mode, sorption experiments were carried out by equilibrating $20 \mathrm{~mL}$ of $100 \mathrm{mg} \mathrm{L} \mathrm{L}^{-1}$ of uranyl ions at $\mathrm{pH} 5$ for $3 \mathrm{~h}$ using $0.05 \mathrm{~g}$ of the adsorbent. The concentration of uranyl ions in the aqueous phase was analyzed by inductive coupled plasma-mass spectrometry (ICP-MS) (Thermo Scientific, XSERIES 2). The amount of uranyl ions adsorbed ( $\mathrm{mg}$ ) per unit mass of the adsorbent (g), $q_{\mathrm{e}}$, was obtained by the equation given below:

$$
q_{\mathrm{e}}=\frac{\left(C_{\mathrm{i}}-C_{\mathrm{e}}\right)}{m} \times V
$$

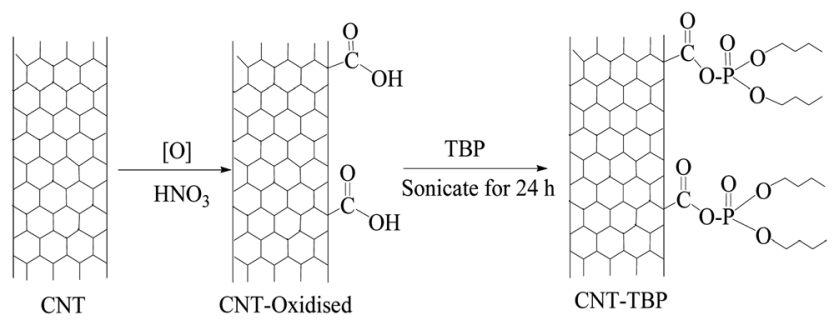

Scheme 1 Preparation of CNT-OX and CNT-TBP where $C_{\mathrm{i}}$ and $C_{\mathrm{e}}$ are the initial and equilibrium concentrations of uranyl ions $\left(\mathrm{mg} \mathrm{L}^{-1}\right), V$ is the volume of the aqueous phase (L), and $m$ is the dry mass of the adsorbent $(\mathrm{g})$. Kinetic experiments were conducted by monitoring the amount of uranyl ions adsorbed at regular time intervals. The amount of $\mathrm{U}(\mathrm{vI})$ adsorption at temperatures $25{ }^{\circ} \mathrm{C}, 35{ }^{\circ} \mathrm{C}$ and $45{ }^{\circ} \mathrm{C}$ was measured for calculating the thermodynamic parameters. The recyclability of CNT-TBP was investigated using $0.1 \mathrm{M} \mathrm{HCl}$ as a desorber.

\subsection{Instrumentation}

Fourier Transform Infra-Red (FTIR) measurements were recorded on a Tensor 27 (Bruker, Germany) in the attenuated total reflectance (ATR) mode. SEM micrographs were acquired using an FEI Quanta 200 machine. TEM analysis was carried out on a Technai G2 T-20 (FEI, Eindhoven, Netherlands) transmission electron microscope operated at $200 \mathrm{kV}$. Using a PHI 5000 Versa Prob II (FEI Inc.) spectrometer with nonmonochromatic $\mathrm{Al} \mathrm{K} \alpha$ radiation $(1486.6 \mathrm{eV})$, XPS measurements were carried out. Individual spectral peaks were deconvoluted using XPSPEAK41 software. For fitting the spectral region a nonlinear Shirley background subtraction was applied. The surface characteristics of the sorbent namely pore size distribution (PSD),

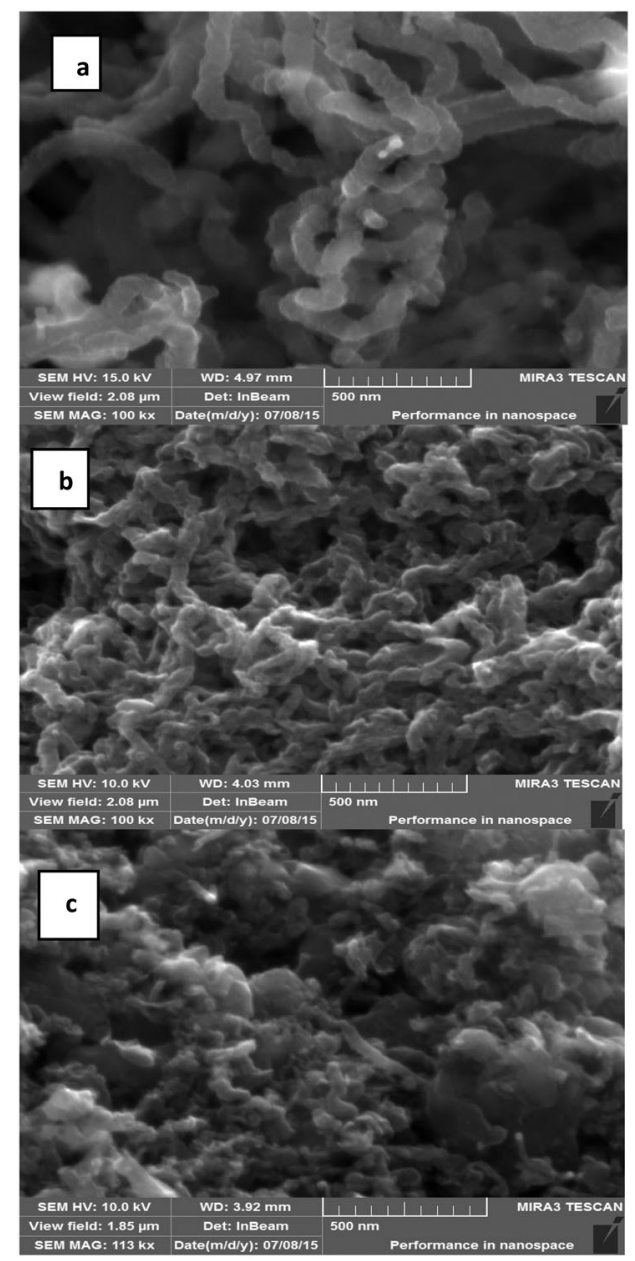

Fig. 1 SEM images of (a) CNT-plain, (b) CNT-OX and (c) CNT-TBP. 


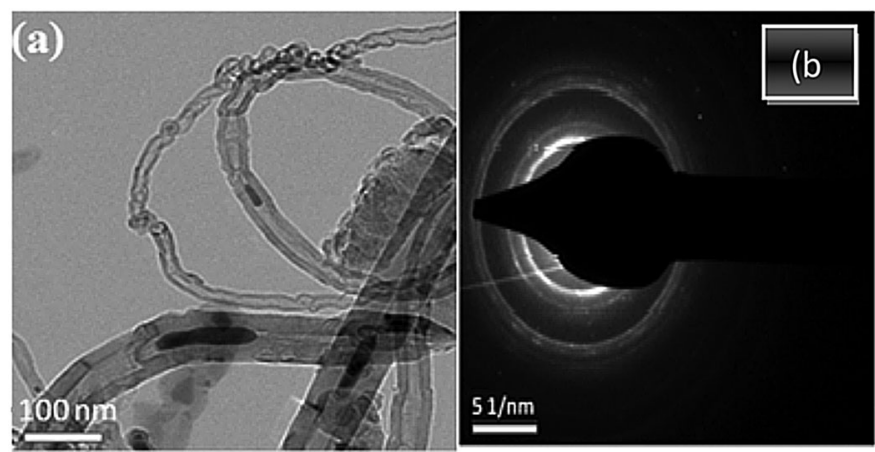

Fig. 2 TEM images of CNT-plain at (a) $100 \mathrm{~nm}$ magnification and (b) electronic diffraction spectra.

pore volume and specific surface area were measured using an Autosorb-1C instrument (Quantachrome, USA). Finally, the concentration of $\mathrm{U}(\mathrm{vI})$ in the aqueous solutions was determined by inductive coupled plasma mass spectroscopy (ICP-MS; Thermo, X-Series2).

\section{Results and discussion}

As described in the Materials and methods section, initially CNTs were synthesized by the floating catalytic chemical vapour deposition method and grafting was carried out by oxidation (CNT-OX) and further treatment with tributyl phosphate (CNT-TBP). Thus the prepared adsorbents viz., CNT-plain, CNT-OX and CNT-TBP were characterized by various techniques including SEM, TEM, BET surface analysis, FTIR, and XPS and evaluated for their applicability towards the removal of uranyl ions.

\subsection{Characterization of adsorbents}

3.1.1 Surface morphology using SEM and TEM. SEM images of plain CNTs, oxidized CNTs, and CNT-TBP are shown in Fig. 1(a)-(c) respectively. The diameter and length of the prepared CNTs were found to be in the range of $20-80 \mathrm{~nm}$ and 1-10 $\mu \mathrm{m}$ respectively (Fig. 1(a)). In CNT-OX (Fig. 1(b)) exfoliated rope like structures are observed. This could be attributed to the etching of graphitic layers of CNTs during oxidation. After oxidation and grafting of the TBP ligand (Fig. 1c) there was no appreciable difference in the surface characteristics which confirms that minimal damage occurred after grafting with the TBP ligand. The HR-TEM image revealed the presence of nanotubes and iron particles located inside the nanotubes (Fig. 2(a)). The corresponding diffraction rings and a bright spot in the electron diffraction pattern (Fig. 2(b)) suggest that the obtained CNTs possess crystalline Fe particles.

3.1.2 FTIR analysis of the prepared sorbents. FTIR spectra of CNT-plain, CNT-OX and CNT-TBP are shown in Fig. 3. A broad peak at $\sim 3430 \mathrm{~cm}^{-1}$ is due to the $\mathrm{O}-\mathrm{H}$ stretch frequency of the hydroxyl group (Fig. 3). The spectra of CNT-OX show peaks at $1720 \mathrm{~cm}^{-1}$ and $1185 \mathrm{~cm}^{-1}$, which are associated with the asymmetric $\mathrm{C}=\mathrm{O}$ and $\mathrm{C}-\mathrm{O}$ stretching band of the carboxylic acid (-COOH) group. ${ }^{15}$ The peak observed at $1574 \mathrm{~cm}^{-1}$ is related to the carboxylate anion stretch mode. The spectrum of CNT-TBP presents

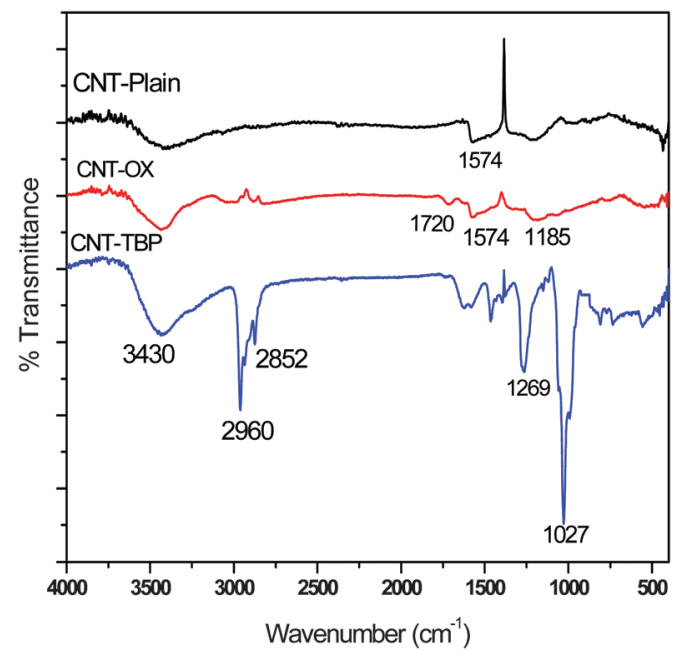

Fig. 3 FTIR spectra of CNT-plain, CNT-OX and CNT-TBP.

the C-H bond stretching at around $2960 \mathrm{~cm}^{-1}$ due to methyl groups on MWCNTs. The signal at $2852 \mathrm{~cm}^{-1}$ can be assigned to the symmetric stretching of $-\mathrm{CH}_{2}-$ groups of the tributyl phosphate moiety. Furthermore, in CNT-TBP, the $\mathrm{P}=\mathrm{O}$ stretching vibration, occurred at $1269 \mathrm{~cm}^{-1}$. The $\mathrm{P}-\mathrm{O}-\mathrm{C}$ vibration occurred at $1027 \mathrm{~cm}^{-1},{ }^{16}$ which proves the grafting of TBP on the CNT surface.

3.1.3 Surface area, pore volume and pore size distribution analysis using BET measurements. The surface characteristics of the plain CNTs, CNT-OX and CNT-TBP were obtained by the standard BET method in a relative pressure range from 0.05 to 0.35 . The nitrogen adsorption-desorption isotherm of CNT-plain is shown in Fig. 4. The material exhibited a type IV behaviour typical of a mesoporous material. The total pore volume, meso, micro and macro pore volumes, were calculated using Quantochrome's software. The surface characteristics of various sorbents prepared are listed in Table 1 . It is evident from the data that the prepared sorbents possessed a small pore size and a large surface area which lead to strong confinement of the adsorbed analyte on the surface of the CNTs. Upon oxidation with nitric acid, the specific surface area increased from $99.8 \mathrm{~m}^{2} \mathrm{~g}^{-1}$ to $111.9 \mathrm{~m}^{2} \mathrm{~g}^{-1}$, which could be attributed to the opening of pores. Further CNT-TBP exhibited a marginal decrease in the surface area which is due to the anchoring of the TBP ligand. 


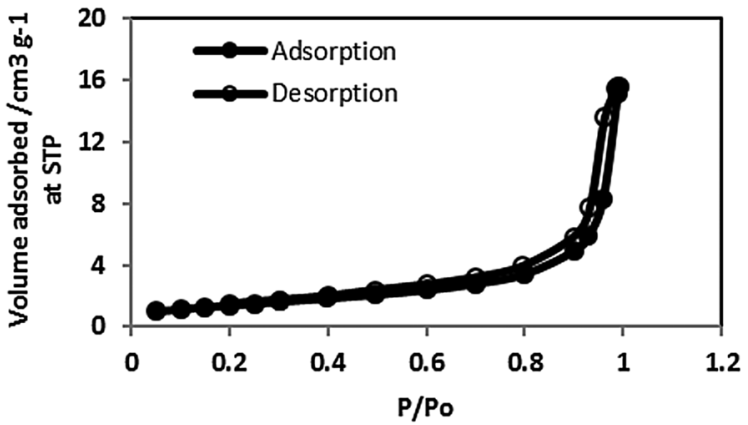

Fig. 4 Nitrogen adsorption isotherm of CNT-plain.

Table 1 Surface characteristics of various prepared CNTs

\begin{tabular}{lcllll}
\hline & $\begin{array}{l}\text { Surface } \\
\text { area } \\
\left(\mathrm{m}^{2} \mathrm{~g}^{-1}\right)\end{array}$ & $\begin{array}{l}\text { Average } \\
\text { diameter } \\
(\mathrm{nm})\end{array}$ & $\begin{array}{l}\text { Total pore } \\
\text { volume } \\
\left(\mathrm{cm}^{3} \mathrm{~g}^{-1}\right)\end{array}$ & Meso volume $\left(\mathrm{cm}^{3} \mathrm{~g}^{-1}\right)$ & Micro \\
\hline CNT-plain & 99.81 & 14.67 & 0.3661 & 0.4280 & 0.0048 \\
CNT-OX & 111.89 & 10.52 & 0.2943 & 0.1681 & 0.0049 \\
CNT-TBP & 102.77 & 18.90 & 0.4861 & 0.4197 & 0.0043
\end{tabular}

\subsection{Mechanism of interaction between the sorbent and the sorbate using XPS and FTIR studies}

To study the interaction of U(vI) with CNT-TBP, XPS spectra were recorded for CNT-TB and CNT-TBP-U. Fig. 5 illustrates the $\mathrm{O} 1 \mathrm{~s}, \mathrm{C} 1 \mathrm{~s}, \mathrm{P} 2 \mathrm{p}$ and $\mathrm{U} 4 \mathrm{f}$ spectra. Uranium loading is observed in CNT-TBP-U evidenced by the appearance of doublet peaks of $\mathrm{U} 4 \mathrm{f}_{5 / 2}$ and $\mathrm{U} 4 \mathrm{f}_{7 / 2}$ with a splitting value of $10.72 \mathrm{eV}$. Table 2 depicts the binding energies of $\mathrm{O} 1 \mathrm{~s}, \mathrm{C} 1 \mathrm{~s}, \mathrm{P} 2 \mathrm{p}$ and the splitting values of the $\mathrm{U}(\mathrm{vr})$ spectra. To get a further insight into the $\mathrm{U}(\mathrm{vI})$ sorption, the core level scans for $\mathrm{C} 1 \mathrm{~s}, \mathrm{O} 1 \mathrm{~s}, \mathrm{P} 2 \mathrm{p}$, and $\mathrm{U} 4 \mathrm{f}$ on CNT-TBP and CNT-TBP-U were analyzed.

The $\mathrm{O} 1 \mathrm{~s}$ and $\mathrm{C}$ 1s spectra of CNT-TBP and CNT-TBP-U are shown in Fig. 6. The peak fitting results of the C 1s, O 1s, P 2p, $\mathrm{U} 4 \mathrm{f}$, before and after $\mathrm{U}(\mathrm{vI})$ loading on CNT-TBP are shown in Table 2. From Fig. 6a, the three main components of the $\mathrm{O} 1 \mathrm{~s}$ spectra occurred at 531.54, 533.56 and $532.87 \mathrm{eV}$, respectively,

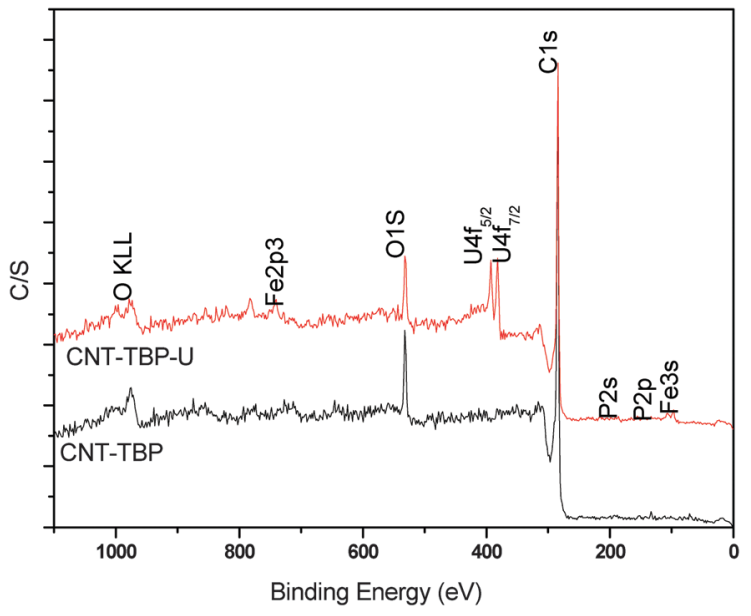

Fig. 5 XPS survey scans of plain and U(VI) loaded CNT-TBP systems.
Table 2 Binding energies (eV) of CNT-TBP before and after uranium sorption

\begin{tabular}{lllllll}
\hline Adsorbent & C 1s & O 1s & P 2p & U 4f5/2 & U 4f7/2 & $\begin{array}{l}\text { Splitting } \\
\text { value }\end{array}$ \\
\hline CNT-TBP & 284.55 & 532.02 & 133.76 & - & - & \\
CNT-TBP-U & 283.65 & 532.47 & 133.97 & 392.87 & 382.15 & 10.72 \\
\hline
\end{tabular}

Table 3 Molecular level binding energies of CNT-TBP and CNT-TBP-U systems

\begin{tabular}{|c|c|c|c|c|c|c|}
\hline \multirow{2}{*}{ Core levels } & \multicolumn{3}{|l|}{ CNT-TBP } & \multicolumn{3}{|l|}{ CNT-TBP-U } \\
\hline & $\begin{array}{l}\text { Binding } \\
\text { energy }(\mathrm{eV})\end{array}$ & $\begin{array}{l}\text { FWHW } \\
(\mathrm{eV})\end{array}$ & Area & $\begin{array}{l}\text { Binding } \\
\text { energy }(\mathrm{eV})\end{array}$ & $\begin{array}{l}\text { FWHW } \\
(\mathrm{eV})\end{array}$ & Area \\
\hline \multirow[t]{4}{*}{ C $1 \mathrm{~s}$} & 285.06 & 0.674 & 1575.04 & 285.87 & 1.25 & 1202.25 \\
\hline & 284.58 & 0.440 & 3307.22 & 284.91 & 0.61 & 1725.39 \\
\hline & 284.25 & 0.484 & 7563.98 & 284.16 & 0.45 & 4136.41 \\
\hline & 286.03 & 1.590 & 1971.61 & 284.46 & 0.43 & 3907.03 \\
\hline \multirow[t]{4}{*}{ O $1 \mathrm{~s}$} & 531.54 & 2.318 & 3263.12 & 531.06 & 1.51 & 1944.42 \\
\hline & 533.56 & 0.890 & 241.96 & 533.21 & 1.07 & 529.58 \\
\hline & 532.87 & 1.073 & 839.65 & 531.76 & 1.79 & 211.65 \\
\hline & & & & 532.29 & 1.22 & 717.02 \\
\hline \multirow[t]{3}{*}{ P 2p } & 133.40 & 1.184 & 148.30 & 133.95 & 1.41 & 121.28 \\
\hline & 134.30 & 1.099 & 82.31 & 134.52 & 1.50 & 12.60 \\
\hline & - & - & - & 133.12 & 0.87 & 38.65 \\
\hline \multirow[t]{2}{*}{$\mathrm{U} 4 \mathrm{f} 7 / 2$} & - & - & - & 381.05 & 1.72 & 990.30 \\
\hline & - & - & - & 382.13 & 1.91 & 1717.22 \\
\hline
\end{tabular}
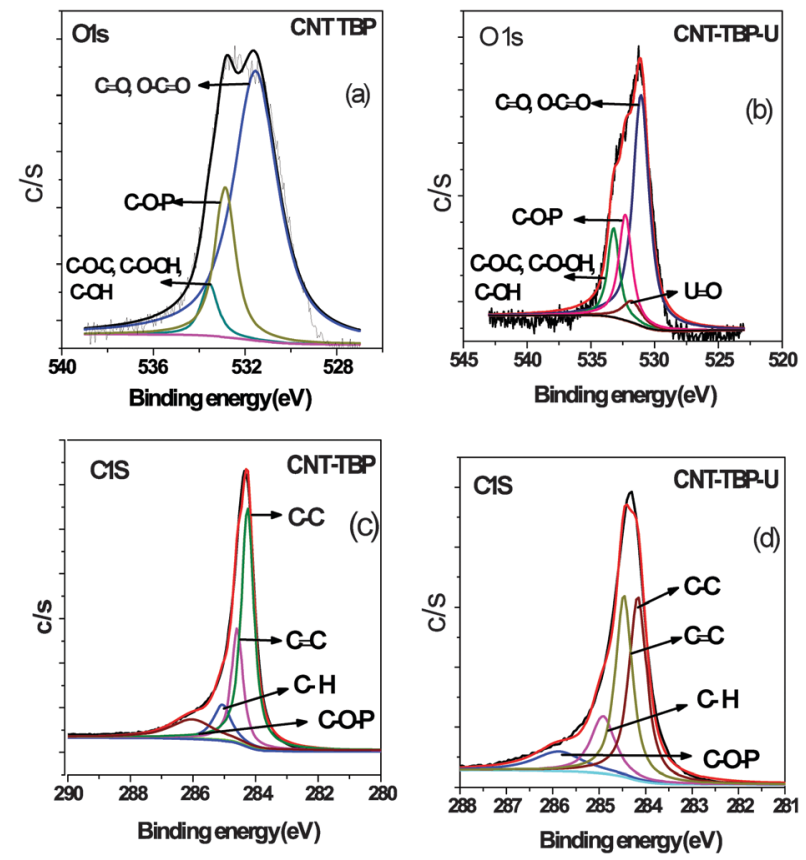

Fig. 6 Curve fitted high resolution scans of (a) $\bigcirc$ 1s of CNT-TBP, (b) $\bigcirc 1 \mathrm{~s}$ of CNT-TBP-U, (c) C1s of CNT-TBP and (d) C 1s of CNT-TBP-U.

corresponding to $\mathrm{C}=\mathrm{O}, \mathrm{O}-\mathrm{C}=\mathrm{O}$ and $\mathrm{C}-\mathrm{O}-\mathrm{C}, \mathrm{C}-\mathrm{O}-\mathrm{OH}, \mathrm{C}-\mathrm{OH}^{17}$ and $\mathrm{C}-\mathrm{O}-\mathrm{P} .{ }^{18}$ Thus the data confirm the grafting of the TBP ligand onto the CNT surface. After U(vI) loading (Fig. 6b), peaks occurred at 531.06, 532.21, 531.76, and $532.29 \mathrm{eV}$. 
The presence of the $\mathrm{U}=\mathrm{O}$ bond is confirmed by the appearance of an additional peak after $\mathrm{U}(\mathrm{vI})$ sorption. ${ }^{19,20}$ Furthermore, after $\mathrm{U}(\mathrm{vI})$ adsorption $\mathrm{O}$ 1s binding energies were shifted to lower values. This further confirms that complexation occurs between the oxygen-containing tributyl phosphate groups and uranyl ions during adsorption.

Fig. $6 \mathrm{c}$ and d shows the molecular level $\mathrm{C}$ 1s of CNT-TBP and CNT-TBP-U respectively. The four individual component peaks of $\mathrm{C} 1 \mathrm{~s}$ occurred at 284.25, 284.58, 285.06 and $286.03 \mathrm{eV}$ corresponding to $\mathrm{C}-\mathrm{C}, \mathrm{C}=\mathrm{C}, \mathrm{C}-\mathrm{H}$ and $\mathrm{C}-\mathrm{O}-\mathrm{P}^{17,18}$ bonds respectively. After uranyl adsorption the peaks shifted to lower binding energies owing to the complexation of the tributyl phosphate group and $\mathrm{U}(\mathrm{vI})$ ions.

Fig. 7a and $\mathrm{b}$ denotes the $\mathrm{P} 2 \mathrm{p}$ spectra of CNT-TBP before and after loading $\mathrm{U}(\mathrm{vI})$ respectively. In CNT-TBP, the binding energy of the $\mathrm{P} 2 \mathrm{p}_{3 / 2}$ component was found at $134.3 \mathrm{eV}$ : the $\mathrm{P} 2 \mathrm{p}$ spectrum is a convolution of the $\mathrm{P} 2 \mathrm{p}_{1 / 2}$ and $\mathrm{P} 2 \mathrm{p}_{3 / 2}$ peaks that were resolved, keeping their branching ratio and their difference equal to 0.9 and $1.8 \mathrm{eV}$, respectively. After uranium sorption (Fig. 7b) the shifting of peaks to higher binding energies was observed. Additionally a new peak was observed at $133.21 \mathrm{eV}$, which could be attributed to the $\mathrm{P}-\mathrm{O}-\mathrm{U}$ bond.

The $\mathrm{U}_{4} \mathrm{f}_{7 / 2}$ spectrum (Fig. 7c) was deconvoluted into two components: the peak corresponding to the free uranyl ion that occurred at $381.05 \mathrm{eV}$ and the peak of covalently bonded oxygen and $\mathrm{U}(\mathrm{vI})$ that occurred at $382.13 \mathrm{eV}$ (Table 3).

From the above discussion it is clear that the TBP ligand is grafted onto CNTs and complexation of uranyl ions occurred with the phosphoryl group of the tributyl phosphate ligand.

Infra red spectra of CNT-TBP before and after U(vI) sorption are shown in Fig. 8. It is evident from the figure that, after $\mathrm{U}(\mathrm{vI})$ sorption, a shift in $\mathrm{P}=\mathrm{O}$ vibration band to $1110 \mathrm{~cm}^{-1}$ was observed. This could be attributed to the coordination of $\mathrm{UO}_{2}{ }^{2+}$
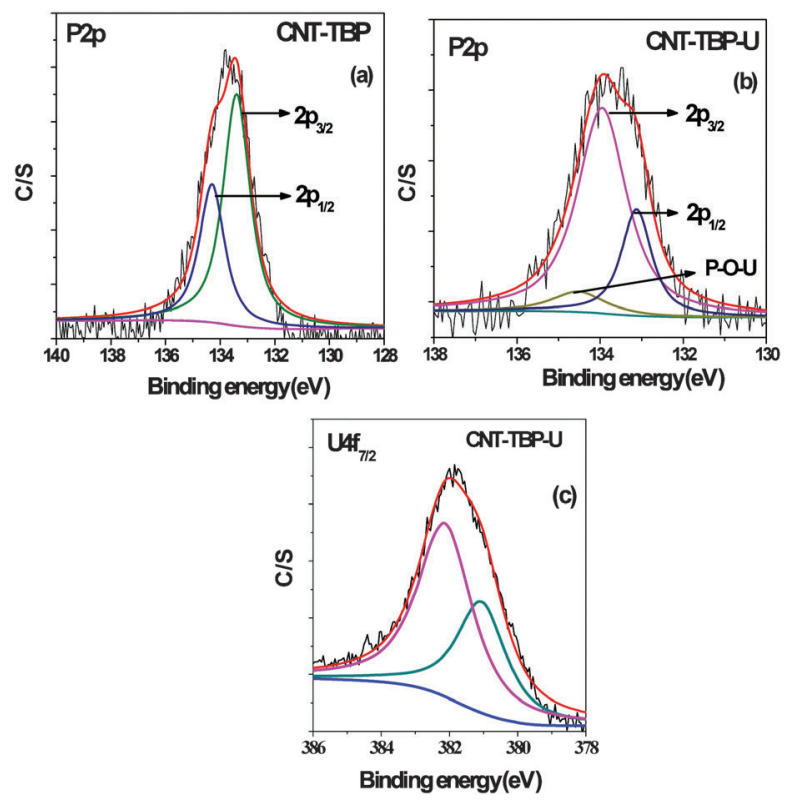

Fig. 7 Curve fitted high resolution scans of (a) P 2p of CNT-TBP (b) P 2p of CNT-TBP-U (c) $\cup 4 \mathrm{f}_{7 / 2}$ of CNT-TBP-U.

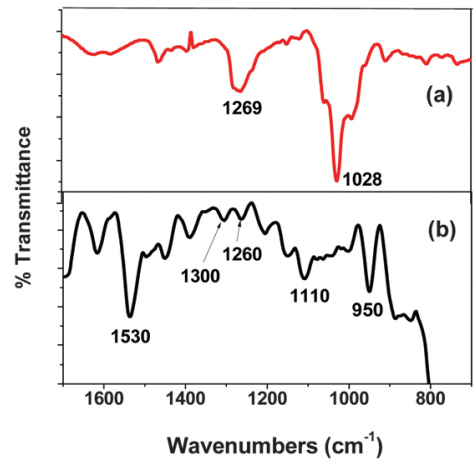

Fig. 8 FTIR scans of (a) CNT-TBP and (b) CNT-TBP-U.

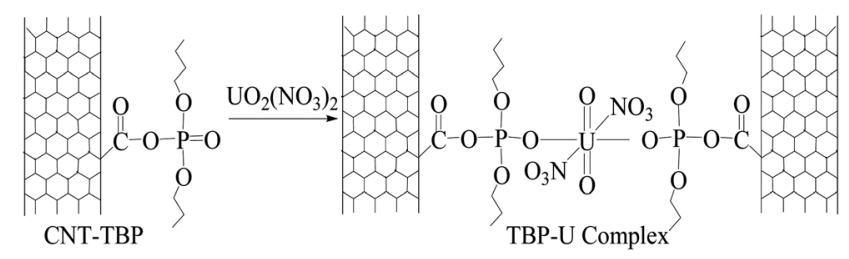

Scheme 2 Schematic representation of $U(\mathrm{VI})$ loading on CNT-TBP.

cations with the $\mathrm{P}-\mathrm{O}$ bond of the TBP molecule. The shift of the $\mathrm{P}=\mathrm{O}$ frequency after $\mathrm{U}(\mathrm{vI})$ sorption was about $82 \mathrm{~cm}^{-1}$, and the magnitude of the frequency shift obtained was consistent with other uranyl complexes with organophosphorus ligands. ${ }^{21,22}$ The mode of nitrate complexation to the metal ion can be determined by the separation $\Delta \nu$ of the symmetric $\nu 1$ and asymmetric $\nu 2 \mathrm{NO}_{2}$ stretching frequencies. ${ }^{23-25}$ A $\Delta \nu$ value $>186 \mathrm{~cm}^{-1}$ indicates a bidentate chelate environment, while a value $\leq 115 \mathrm{~cm}^{-1}$ indicates a monodentate coordination. It is evident from the spectra that $\Delta \nu=270 \mathrm{~cm}^{-1}\left(\nu 1\right.$ at $1300 \mathrm{~cm}^{-1}$ and $\nu 2$ at $1530 \mathrm{~cm}^{-1}$ ) was obtained which indicated a bidentate chelation of the nitrate ion to the uranyl ion. Further an additional vibration occurred at $950 \mathrm{~cm}^{-1}$ which could be assigned to the asymmetric stretching frequency of the $\mathrm{U}=\mathrm{O}$ bond. ${ }^{26}$ Based on the above discussions the following reaction scheme has been proposed (Scheme 2) for the sorption of the uranyl ion and CNT-TBP.

\subsection{The effect of initial $\mathrm{pH}$ on sorption}

The initial $\mathrm{pH}$ of the solution containing $100 \mathrm{mg} \mathrm{L}^{-1}$ of uranyl ions was varied from 2 to 8 and equilibrium experiments were carried out (Fig. 9). The amount of uranyl ions adsorbed increased from pH 4 to 6 and a further increase in $\mathrm{pH}$ resulted in decreased sorption. The adsorption trends observed over the $\mathrm{pH}$ range studied could be assigned to the distribution of various uranyl species. It is well known that at $\mathrm{pH}$ values $\leq 3$, $\mathrm{UO}_{2}{ }^{2+}$ is the predominant species ${ }^{11}$ and in the $\mathrm{pH}$ range of 4.0-9.0 hydrolysis of $\mathrm{U}(\mathrm{vI})$ occurred and other uranyl complexes, including $\mathrm{UO}_{2}(\mathrm{OH})^{+},\left(\mathrm{UO}_{2}\right)_{2}(\mathrm{OH})_{2}{ }^{2+}$ and $\left(\mathrm{UO}_{2}\right)_{3}(\mathrm{OH})_{5}{ }^{+27}$ were prevalent. However at $\mathrm{pH}$ values $>7.0$ anionic uranyl species $\left(\mathrm{UO}_{2}\right)_{3}(\mathrm{OH})_{7}^{-}$also coexisted. ${ }^{28}$ The lower adsorption rate of uranyl ions at $\mathrm{pH}$ values $<4$ could be attributed to the 


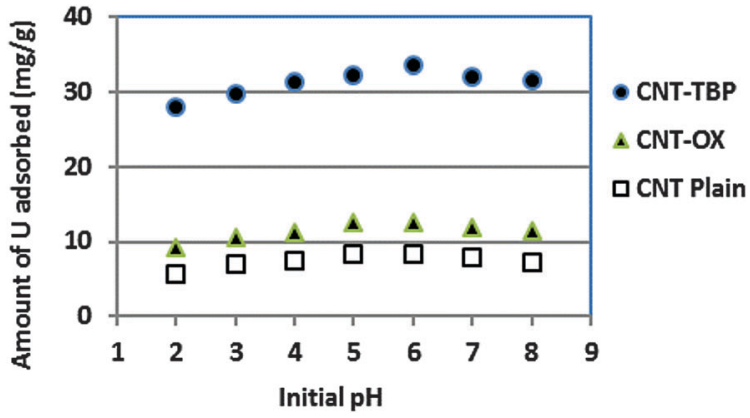

Fig. 9 Effect of initial pH on sorption of $U(\mathrm{VI})$ with CNT-plain, CNT-OX and CNT-TBP.

competition of protons for the active surface of CNTs. Thus adsorption of uranyl ions was found to be maximum at around
pH 5 for CNT-TBP and at pH 6 for CNT-OX and CNT plain. At $\mathrm{pH}>7$ negatively charged uranyl complexes were repelled by the negative surface charge of the sorbent thus resulting in a lower capacity. Due to functionalization of the TBP ligand onto CNTs the amount of uranyl ions adsorbed was found to be higher for CNT-TBP compared to plain and oxidized CNTs.

\subsection{Kinetics of sorption}

The adsorption of an aqueous solution containing $\mathrm{U}(\mathrm{vI})$ on CNT-plain, CNT-OX and CNT-TBP was carried out at $\mathrm{pH}$ $5.0 \pm 0.1$ to investigate the kinetics of sorption. Fig. 10a shows the adsorption process on various sorbents for $\mathrm{U}(\mathrm{vI})$ removal. A contact time of $3.0 \mathrm{~h}$ was sufficient for the adsorption of uranyl ions onto CNT-TBP to reach equilibrium. However, CNT-plain and CNT-OX reach equilibrium at $3.5 \mathrm{~h}$. The kinetics of $\mathrm{U}(\mathrm{vI})$
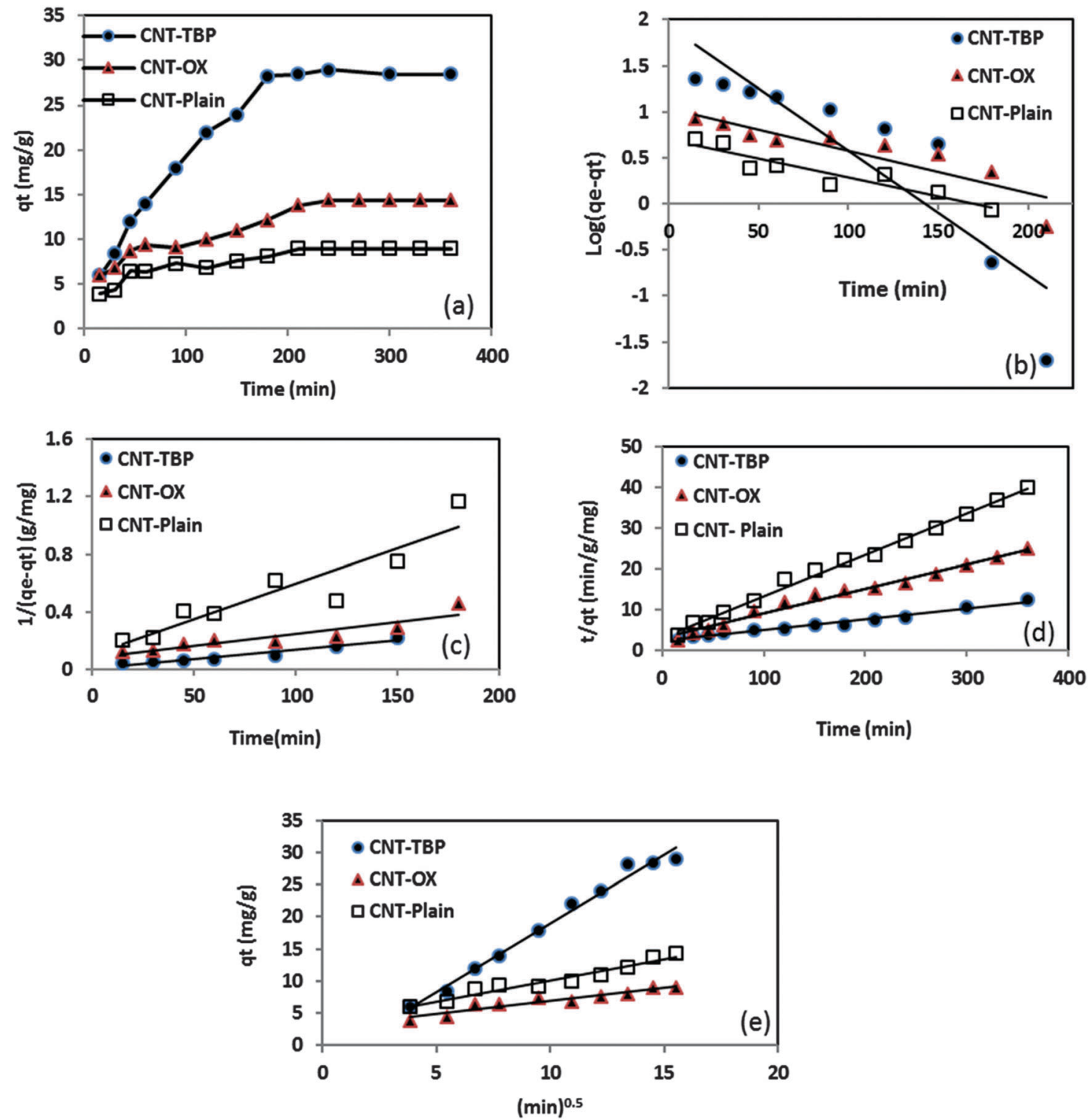

Fig. 10 (a) Equilibration time, (b) pseudo first order kinetics, (c) second order kinetics, (d) pseudo second order kinetics and (e) Web-Morris model of CNT-TBP and $U(\mathrm{~V})$. 
Table 4 Kinetic rate constants of the sorption of $U(\mathrm{vI})$ by various CNTs

\begin{tabular}{|c|c|c|c|c|c|c|c|c|}
\hline Adsorbent & \multicolumn{2}{|c|}{$\underline{\text { Pseudo first order }}$} & \multicolumn{2}{|l|}{$\underline{\text { Second order }}$} & \multicolumn{2}{|c|}{ Pseudo second order } & \multicolumn{2}{|l|}{ Web-Morris model } \\
\hline CNT-OX & 0.004 & 0.803 & 0.005 & 0.859 & 0.0012 & 0.981 & 0.409 & 0.906 \\
\hline CNT-TBP & 0.013 & 0.800 & 0.001 & 0.926 & 0.0003 & 0.978 & 2.147 & 0.986 \\
\hline
\end{tabular}

adsorption onto all the sorbents prepared were modelled using the Lagergren model $^{29}$ or using pseudo first order, second order $^{30}$ or pseudo second order models ${ }^{31}$ as shown in the following equations:

$$
\begin{gathered}
\log \left(q_{\mathrm{e}}-q_{t}\right)=\log q_{\mathrm{e}}-\frac{k_{1}}{2.303} t \\
\frac{1}{q_{\mathrm{e}}-q_{t}}=\frac{1}{q_{\mathrm{e}}}+k_{2} t \\
\frac{t}{q_{t}}=\frac{1}{k_{2}{ }^{\prime} q_{\mathrm{e}}{ }^{2}}+\frac{t}{q_{\mathrm{e}}}
\end{gathered}
$$

where $k_{\mathrm{L}}$ is the Lagergren rate constant of sorption $\left(\mathrm{min}^{-1}\right)$; $k_{2}$ the second-order rate $\left(\mathrm{g} \mathrm{mg}^{-1} \mathrm{~min}^{-1}\right)$ and $k_{2}^{\prime}$ the pseudosecond-order rate constant of sorption $\left(\mathrm{g} \mathrm{mg}^{-1} \mathrm{~min}^{-1}\right) ; q_{\mathrm{e}}$ and $q_{\mathrm{t}}$ are the amounts of uranyl ions sorbed $\left(\mathrm{mg} \mathrm{g}^{-1}\right)$ at equilibrium and at a given time $t$, respectively. The kinetic model plots are shown in Fig. 10b-d. From Table 4, it is evident that among various models, a pseudo second order plot of $t / q_{t} v s . t$ (Fig. 10d) yielded a regression coefficient $>0.978$. Thus, it could be concluded that the adsorption of uranyl ions with the prepared sorbents followed a pseudo second order kinetic model. Furthermore, the Weber and Morris model ${ }^{32}$ describes the intraparticle diffusion between the sorbent and the sorbate. This model correlates the amount of the solute adsorbed and the intraparticle diffusion rate constant $\left(k_{\text {int }}\right)$ given by the following equation:

$$
q_{t}=k_{\text {int }} \sqrt{t}+C
$$

It is evident from Fig. 10e that the plot of $q_{t} v s . \sqrt{t}$ yields an intercept and this confirms that in addition to intraparticle diffusion, chemisorptions could also be involved. The values obtained from this model are presented in Table 4.

\subsection{Equilibrium studies}

Sorption data of uranyl ions with various CNTs were modelled using commonly used isotherms (Fig. 11). The Langmuir model describes the monolayer adsorption and equivalency of the surface adsorption sites. The linear Langmuir model ${ }^{33}$ could be expressed as

$$
\frac{1}{q_{\mathrm{e}}}=\frac{1}{q_{0} C_{\mathrm{e}} K_{\mathrm{L}}}+\frac{1}{q_{\mathrm{m}}}
$$

where $C_{\mathrm{e}}$ is the equilibrium concentration $\left(\mathrm{mg} \mathrm{L}^{-1}\right)$ and $q_{\mathrm{e}}$ is the amount of $\mathrm{U}(\mathrm{vI})$ sorbed $\left(\mathrm{mg} \mathrm{g}^{-1}\right)$ at equilibrium. The empirical constants $b$ and $q_{\mathrm{m}}$ denote the energy of adsorption and the maximum adsorption capacity, respectively. The results obtained for the various model parameters are listed in Table 5.

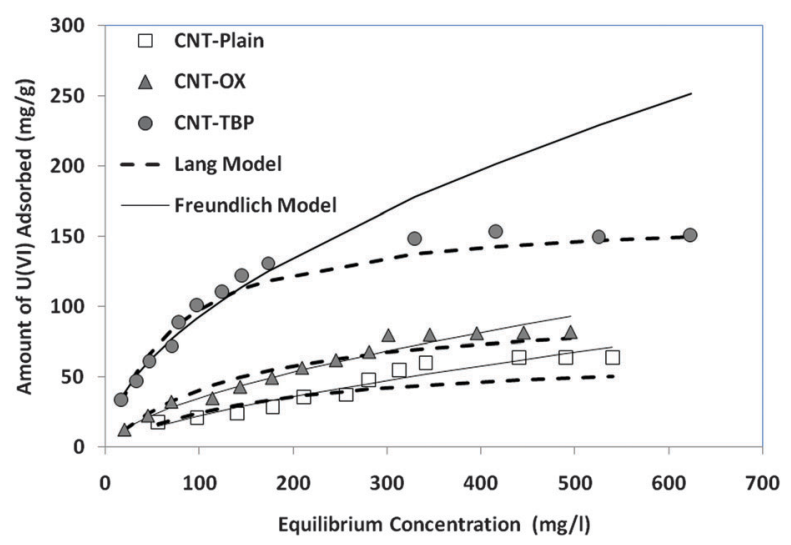

Fig. 11 Adsorption isotherms of various adsorbents with $U(\mathrm{vI})$.

The Langmuir adsorption capacity of the prepared adsorbents towards uranyl ions was in the order of CNT-TBP > CNT-OX > CNT-plain. The adsorption capacity of CNT-TBP was found to be 2.5 times higher than the plain CNTs. The complexing ability of the TBP ligand towards $\mathrm{U}(\mathrm{vI})$ resulted in an increased sorption capacity. A comparison of the prepared adsorbents with other functionalized CNTs reported in the literature is given in Table 6. For example, the capacity obtained for CNTTBP is higher than plain oxidized MWCNTs ${ }^{28}\left(43.30 \mathrm{mg} \mathrm{g}^{-1}\right)$, diglycolamide functionalized MWCNTs ${ }^{34}\left(133.7 \mathrm{mg} \mathrm{g}^{-1}\right)$, carboxymethyl cellulose grafted $\mathrm{CNTs}^{35}\left(112.0 \mathrm{mg} \mathrm{g}^{-1}\right)$, imine functionalized carbon spheres $^{36}\left(113 \mathrm{mg} \mathrm{g}^{-1}\right)$ and palm shell activated carbon ${ }^{37}\left(51.81 \mathrm{mg} \mathrm{g}^{-1}\right)$. A comparison of the adsorption capacities of various functionalized CNTs is given in Table 6. The linear Freundlich model is represented below ${ }^{38}$

$$
\log q_{\mathrm{e}}=\frac{1}{n_{\mathrm{F}}} \log C_{\mathrm{e}}+\log K_{\mathrm{F}}
$$

\begin{tabular}{|c|c|c|c|c|c|c|}
\hline \multirow[b]{2}{*}{ Adsorbent } & \multicolumn{3}{|c|}{ Langmuir model } & \multicolumn{3}{|c|}{ Freundlich model } \\
\hline & $\begin{array}{l}q_{\max } \\
\left(\mathrm{mg} \mathrm{g}^{-1}\right)\end{array}$ & $\begin{array}{l}b \\
\left(\mathrm{~L} \mathrm{mg}^{-1}\right)\end{array}$ & $R^{-2}$ & $\begin{array}{l}K_{\mathrm{F}} \\
\left(\mathrm{L} \mathrm{g}^{-1}\right)\end{array}$ & $n_{\mathrm{F}}$ & $R^{2}$ \\
\hline CNT-plain & 66.66 & 0.0057 & 0.845 & 0.918 & 1.445 & 0.926 \\
\hline CNT-OX & 100.00 & 0.0223 & 0.985 & 2.138 & 1.645 & 0.981 \\
\hline CNT-TBP & 166.66 & 0.0142 & 0.972 & 7.533 & 1.835 & 0.964 \\
\hline
\end{tabular}

$K_{\mathrm{F}}$ and $n_{\mathrm{F}}$ represent the sorption intensity and sorption capacity, respectively. Values of " $n_{\mathrm{F}}$ " ranging between 1 and 10 indicate a good adsorbent. In the present study (Table 5) the ' $n$ ' values ranged between 1.445 and 1.835. This signifies the good

Table 5 Isotherm parameters of CNT-plain, CNT-OX and CNT-TBP 
Table 6 Comparison of the maximum adsorption capacities of various functionalized CNTs towards U(VI) removal

\begin{tabular}{lcl}
\hline & $\begin{array}{l}\text { Maximum } \\
\text { adsorption } \\
\text { capacity }\left(\mathrm{mg} \mathrm{g}^{-1}\right)\end{array}$ & Reference \\
\hline Adsorbent & 66.16 & 39 \\
\hline Plasma functionalized MWCNTs & 43.30 & 28 \\
Oxidized MWCNTs & 133.70 & 34 \\
$\begin{array}{l}\text { Diglycolamide functionalized } \\
\text { MWCNTs }\end{array}$ & 33.30 & \\
Oxidized MWCNTs & 112.00 & 10 \\
Carboxymethyl cellulose & & 35 \\
functionalized CNTs & 45.90 & 11 \\
Oxidized MWCNTs & 100.0 & 40 \\
Graphene oxide-CNTs & 145.0 & 41 \\
Amidoxime-CNTs & 20.76 & 42 \\
Montmorillonite@C & 212.7 & 43 \\
CoFe $\mathrm{O}_{4} /$ MWCNTs & 66.66 & Present work \\
CNT-plain & 100.00 & Present work \\
CNT-OX & 166.66 & Present work \\
CNT-TBP & &
\end{tabular}

adsorption capabilities of CNT, CNT-OX and CNT-TBP towards the uranyl ion.

\subsection{Thermodynamic studies}

The feasibility of adsorption was elucidated using thermodynamic parameters like $\Delta G^{\circ}, \Delta H^{\circ}$ and $\Delta S^{\circ}$ which were calculated using the adsorption data. Initially, the constant $K_{\mathrm{c}}$ was calculated using the ratio of $\mathrm{U}(\mathrm{vI})$ adsorbed onto the sorbent $C_{\mathrm{A}}\left(\mathrm{g} \mathrm{L} \mathrm{L}^{-1}\right)$ to that in the aqueous phase at equilibrium $C_{\mathrm{e}}\left(\mathrm{g} \mathrm{l}^{-1}\right)$ given by the following equation:

$$
K_{\mathrm{C}}=\frac{C_{\mathrm{A}}}{C_{\mathrm{e}}}
$$

Then, $\Delta G^{\circ}$ was determined using the following equation:

$$
\Delta G^{\circ}=-R T \ln K_{\mathrm{c}}
$$

where $R$ is the gas constant and $T$ is the temperature in Kelvin. Further, $\Delta S^{\circ}$ and $\Delta H^{\circ}$ were determined using the following Van't Hoff equation:

$$
\log K_{\mathrm{c}}=\frac{\Delta S^{\circ}}{2.303}-\frac{\Delta H^{\circ}}{2.303 R T}
$$

A plot of $\log K_{\mathrm{c}} v s .1 / T$ was obtained for the uranyl ions and the CNT-TBP system (Fig. 12). The thermodynamic parameters namely $\Delta H^{\circ}$ and $\Delta S^{\circ}$ were determined from the slope and intercept, respectively. Table 7 lists the values obtained for various thermodynamic parameters. The negative Gibbs free energy indicated the effectiveness and spontaneity of the sorption process. The endothermic nature of the adsorption process is revealed by the positive enthalpy $\left(\Delta H^{\circ}\right)$ values. Positive entropy $\left(\Delta S^{\circ}\right)$ values could be due to the dehydration of uranyl ions during adsorption.

\subsection{Desorption and recyclability studies}

After adsorption of uranyl ions using CNT-TBP as a sorbent, desorption studies of uranium were conducted. It was found that $0.1 \mathrm{M} \mathrm{HCl}$ efficiently stripped adsorbed uranium ions. The amount of uranyl ions adsorbed and desorbed for three

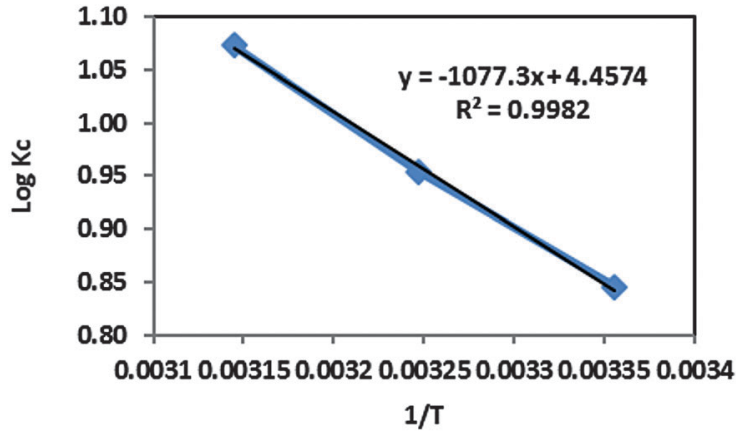

Fig. 12 Thermodynamic studies of CNT-TBP and U(VI) systems.

Table 7 Thermodynamic parameters of CNT-TBP and U(vI)

\begin{tabular}{llrlll}
\hline $\mathrm{T}(\mathrm{K})$ & $\begin{array}{l}C_{\mathrm{e}} \\
\left(\mathrm{g} \mathrm{L}^{-1}\right)\end{array}$ & \multicolumn{1}{c}{$K_{\mathrm{c}}$} & $\begin{array}{l}\Delta G \\
\left(\mathrm{KJ} \mathrm{mol}^{-1}\right)\end{array}$ & $\begin{array}{l}\Delta S \\
\left(\mathrm{~J} \mathrm{~mol}^{-1}\right)\end{array}$ & $\begin{array}{l}\Delta H \\
{\left[\mathrm{~kJ}(\mathrm{~mol} \mathrm{~K})^{-1}\right]^{-1}}\end{array}$ \\
\hline 298 & 12.5 & 7.00 & -4.81 & & \\
308 & 10.0 & 9.00 & -5.63 & 10.26 & 20.62 \\
318 & 7.8 & 11.82 & -6.53 & & \\
\hline
\end{tabular}

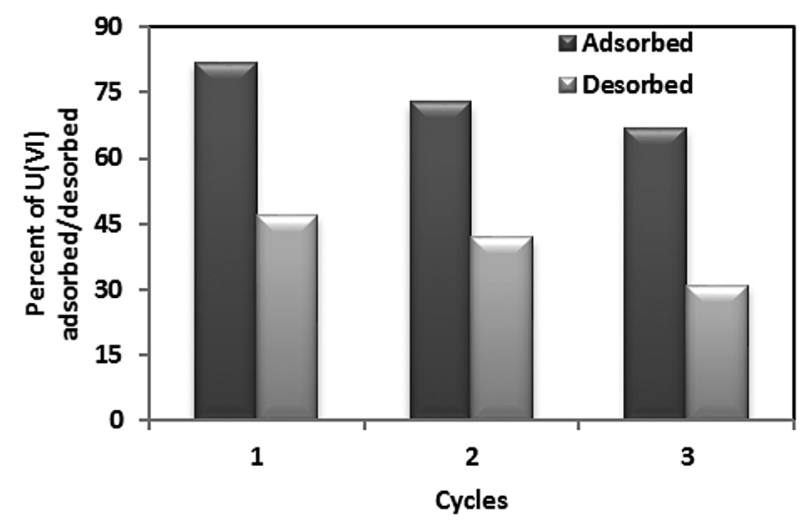

Fig. 13 Desorption and recyclability studies.

consecutive cycles using CNT-TBP as a sorbent is shown in Fig. 13. A decreased U(vi) uptake in the order of 11 and $20 \%$ were observed at the end of the 1st and 2nd cycles, respectively. Using ordered mesoporous carbon ${ }^{12}$ and functionalized activated carbon fibers ${ }^{9}$ as adsorbents similar results were observed.

\section{Conclusions}

The chemical vapour deposition technique was used to synthesize carbon nanotubes using ferrocene in benzene as the hydrocarbon source. Ferrocene acted both as a floating catalyst and as a hydrocarbon source. Efficient functionalization was carried out by oxidation with nitric acid and grafting with the tributyl phosphate ligand. FTIR and XPS studies confirmed the presence of a phosphoryl group on CNT-TBP. A pseudo second order model was found to fit the experimental data. A Langmuir adsorption capacity of $166.6 \mathrm{mg} \mathrm{g}^{-1}$ was obtained for CNTTBP with a high regression coefficient. Efficient complexation of $\mathrm{U}(\mathrm{vI})$ and the TBP ligand resulted in a high sorption capacity 
compared to CNT and CNT-OX. The spontaneity of the reaction was revealed by thermodynamic studies and desorption and recyclability studies were carried out for 3 cycles. FTIR and XPS showed the involvement of the phosphoryl group of the TBP ligand towards the interaction of uranium.

\section{Acknowledgements}

The funding received from the Board of Research in Nuclear Sciences, Department of Atomic Energy, Mumbai, India (Ref. No. 2013/36/57-BRNS/2482) to carry out this work is gratefully acknowledged.

\section{References}

1 K. Sakr, M. S. Sayed and M. B. Hafez, J. Radioanal. Nucl. Chem., 2003, 256, 179.

2 T. Ozdemir and A. Usanmaz, Prog. Nucl. Energy, 2009, 51, 240.

3 B. Allard, U. Olofsson and B. Torstenfelt, Inorg. Chim. Acta, 1984, 94, 205.

4 G. M. Naja and B. Volesky, Toxicity and sources of heavy metals of $\mathrm{Pb}, \mathrm{Cd}, \mathrm{Hg}, \mathrm{Cr}, \mathrm{As}$ and radionucleides in the environment, CRC Press, Taylor and Francis Group, USA, 2009, p. 16.

5 WHO, Guidelines for Drinking Water Quality, Geneva, 2nd edn, 1998, p. 283.

6 P. D. Bhalara, D. Punetha and K. Balasubramanian, J. Environ. Chem. Eng., 2014, 2, 1621.

7 M. Caccin, F. Giacobbo, M. Da Ros, L. Besozzi and M. Mariani, J. Radioanal. Nucl. Chem., 2013, 297, 9.

8 A. M. A. Morsy and A. E. M. Hussein, J. Radioanal. Nucl. Chem., 2011, 288, 341.

9 S. Mishra, J. Dwivedi, A. Kumar and N. Sankararamakrishnan, RSC Adv., 2015, 5, 33023.

10 Y. Sun, S. Yang, G. Sheng, Z. Gua and X. Wang, J. Environ. Radioact., 2012, 105, 40.

11 A. Schierz and H. Zanker, Environ. Pollut., 2009, 157, 1088.

12 B.-W. Nie, Z.-B. Zhang, X.-H. Cao, Y.-H. Liu and P. Liang, J. Radioanal. Nucl. Chem., 2012, 295, 663.

13 P. Giridhar, K. A. Venkatesan, T. G. Srinivasan and P. R. Vasudeva Rao, J. Radioanal. Nucl. Chem., 2005, 265, 31.

14 N. Sankararamakrishnan, D. Chauhan and J. Dwivedi, Chem. Eng. J., 2016, 284, 599.

15 B. Chen, Z. Zhu, J. Ma, Y. Qiu and J. Chen, J. Mater. Chem., 2013, 1, 11355.

16 M. Alibrahim and H. Shlewit, Period. Polytech., Chem. Eng., 2007, 51, 57.

17 V. Datsyuk, M. Kalyva, K. Papagelis, J. Parthenios, D. Tasis, A. Siokou, I. Kallitsisc and C. Galiotis, Carbon, 2008, 46, 833.
18 A. Rossi, F. M. Pirasa, D. Kim, A. J. Gellman and N. D. Spencer, Tribol. Lett., 2006, 23, 197.

19 S. Van den Berghe, F. Miserque, T. Gouder, B. Gaudreau and M. Verwerft, J. Nucl. Mater., 2001, 294, 168.

20 S. Chen, J. Hong, H. Yang and J. Yang, J. Environ. Radioact., 2013, 126, 253.

21 L. L. Burger, in Physical properties, Science and Technology of Tributyl phosphate, ed. W. W. Schulz and J. D. Navratil, CRC Press, Boca Raton, Florida, 1984, p. 26.

22 D. F. Peppard and J. R. Ferraro, J. Inorg. Nucl. Chem., 1959, 10, 275.

23 B. M. Gatehouse, S. E. Livingstone and R. S. Nyholm, Chem. Soc. Rev., 1959, 4222.

24 N. F. Curtis and Y. M. Curtis, J. Inorg. Chem., 1965, 4, 804. 25 J. R. Ferraro and D. F. Peppard, Nucl. Sci. Eng., 1963, 16, 389. 26 K. W. Bagnall and M. W. Wakerley, J. Inorg. Nucl. Chem., 1975, 37, 329.

27 G. Wang, J. Liu, X. Wang, Z. Xie and N. Deng, J. Hazard. Mater., 2009, 168, 1053.

28 M. Wang, J. Qiu, X. Tao, C. Wu, W. Cui, Q. Liu and S. Lu, J. Radioanal. Nucl. Chem., 2011, 288, 895.

29 S. Lagergren, K. Sven. Vetenskapsakad. Handl., 1898, 24, 1-39.

30 Y. S. Ho, D. A. J. Wase and C. F. Forster, Environ. Technol., 1996, 17, 71.

31 Y. S. Ho and G. McKay, Advances in Adsorption Separation Science and Technology, South China University of Technology Press, Guangzhou, 1997, 257.

32 W. J. Weber and J. C. Morris, J. Sanit. Eng. Div., Am. Soc. Civ. Eng., 1963, 89, 31.

33 I. Langmuir, J. Am. Chem. Soc., 1918, 40, 1361.

34 A. K. S. Deb, P. Ilaiyaraja, D. Ponraju and B. Venkatraman, J. Radioanal. Nucl. Chem., 2012, 291, 877.

35 D. Shao, Z. Jiang, X. Wang, J. Li and Y. Meng, J. Phys. Chem. B, 2009, 113, 860.

36 P. S. Dubey, D. A. Dwivedi, M. Sillanpaa, Y.-N. Kwon and C. Lee, RSC Adv., 2014, 4, 46114.

37 Z.-J. Yi, J. Yao, J.-S. Xu, M.-S. Chen, W. Li, H.-L. Chen and F. Wang, J. Radioanal. Nucl. Chem., 2014, 301, 695.

38 H. M. F. Freundlich, J. Phys. Chem., 1906, 57, 385.

39 M. Song, Q. Wang and Y. Meng, J. Radioanal. Nucl. Chem., 2012, 293, 899.

40 Z. Gu, Y. Wang, J. Tang, J. yang, J. Liao, Y. Yang and N. Liu, J. Radioanal. Nucl. Chem., 2015, 303, 1835.

41 Y. Wang, Z. Gu, J. Yang, J. Liao, Y. Yang, N. Liu and J. Tang, Appl. Surf. Sci., 2014, 320, 10.

42 R. Zhang, C. Chen, J. Li and X. Wang, Appl. Surf. Sci., 2015, 349, 129.

43 L. Tan, Q. Liu, X. Jing, J. Liu, D. Song, S. Hu, L. Liu and J. Wang, Chem. Eng. J., 2015, 273, 307. 